The Early Career Section is a new community project, featured here in the Notices. This column will provide information and suggestions for graduate students, job seekers, junior academics of all types, and those who mentor them Angela Gibney is the editor of the Early Career section. Angela Gibney will serve as the editor of this section.

\title{
Introducing the Notices Early Career Section
}

\section{A. Gibney}

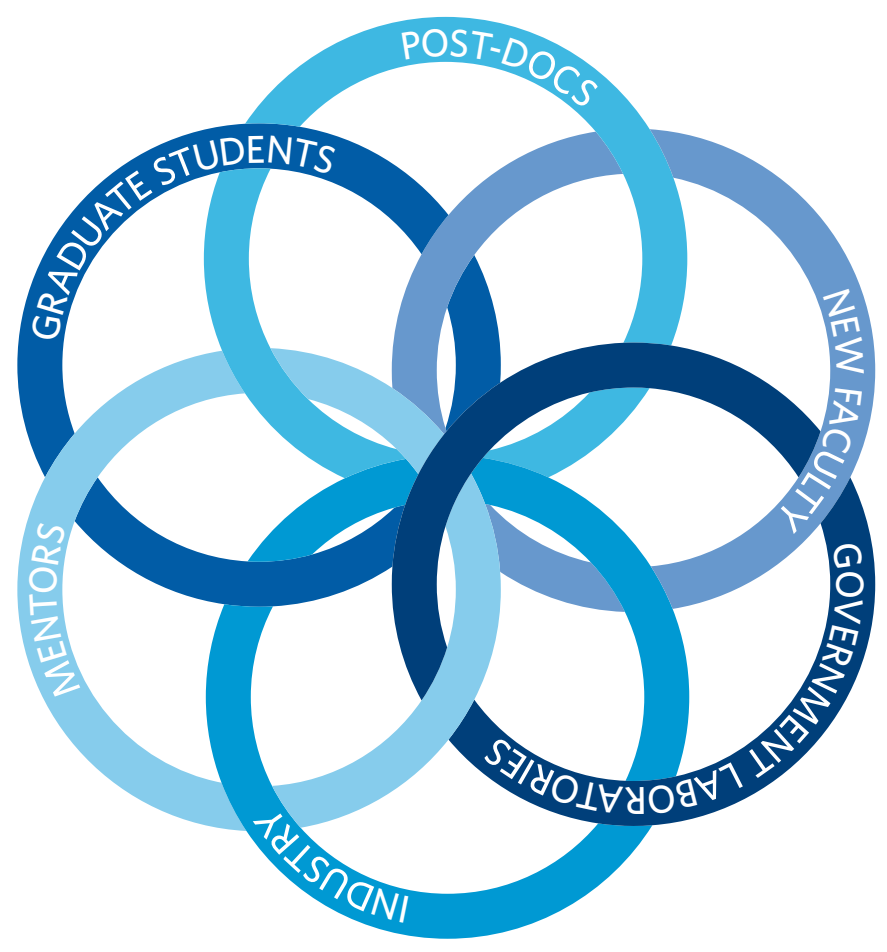

Angela Gibney is professor of mathematics at Rutgers University and associate editor of Notices. Her email address is angela.gibney @gmai1. com.

For permission to reprint this article, please contact: reprint -permission@ams.org.

DOI: https://dx.doi.org/10.1090/noti 1782
It is well understood that the path to an interesting career is just not easy. The road, while at times adventurous, is generally long, sometimes hard, and often hard to find. How can you manage it, to arrive in one piece?

The Early Career Section is a new community project, featured here in the Notices. This column will provide information and suggestions for graduate students, job seekers, junior academics of all types, and those who mentor them. We will consider different aspects of the profession, arranged in themes for each issue, with articles written by mathematicians about topics surrounding that theme. As a first contribution, Rob Lazarsfeld has written a piece about mathematical journaling.

In February we consider issues surrounding the world of research. One of the biggest steps taken by graduate students in this realm is to select a thesis advisor, and Robert Lipshitz will discuss this. Ellen Eischen will weigh in on strategies for moving ahead in one's research, and Chris Woodward about getting new ideas for projects. Kelly Jabbusch will write about Mathematical Reviews ${ }^{\circledR}$, which can be a tremendous tool for learning about the literature, and also a way to contribute to the community. Sam Payne and Amanda Folsom will discuss aspects of doing research with undergraduate students, describing the program SUMRY at Yale University.

We chose March for the "Writing Issue" as it is generally around the time graduate students are starting to finish their thesis and prepare the corresponding paper for publication. It may seem counterintuitive, but writing is one of the central aspects of the work we do as mathematicians. John Etnyre has contributed a piece about writing an introduction to help you maximize the chances people will appreciate your work. Julia Hartmann will address aspects of writing up one's work and submitting it to a journal, and Arend Bayer will discuss referee reports, both writing them 
and reading and responding to them. Joe Silverman will share advice about writing a book, and Jordan Ellenberg about writing math for the general public.

In April, those who plan to go on the non-academic job market generally start the job application process. Often there is a lack of knowledge about options available and ways to make connections with employers. The April issue is about nonacademic math careers and is meant to be a resource for the community of job seekers and those who advise them. Jesse Johnson will write a piece on transitioning to jobs outside of academia. Jim Gatheral will write about careers in financial engineering, Petter Kolm describes careers in quantitative finance, and Emilie Purvine will write about careers at the National Labs.

In May we begin to look ahead to summer break, and many will be thinking about how to get the most out of this big block of free time. Some graduate students will have a choice of summer schools and conferences, and for many junior researchers, it may be a good idea to think about organizing such activities. We plan to take on these topics with articles about how to find good conferences and summer schools for the next year (how to look, how to apply, how to choose what is best); and why folks who are in their early careers could benefit from organizing activities for others. Daniel Krashen will write an article on the nuts and bolts of conference organization in general. Brendan Hassett will contribute a piece about opportunities at the math institutes. We also plan to have an article about how to use free time productively.

Deep into summer break when the June/July issue of the Notices arrives in the mail, people are reminded that they need to make a plan for the coming academic year. This edition will be devoted to getting ready for the academic job market, and applying for grants. Holly Krieger will write about the importance of a good website and online presence, as well as about seeking a job at a research focused institution. Linda Chen will write about seeking a job at a liberal arts institution. John Etnyre will discuss writing grant proposals. Diane Maclagan will write about two-body issues and the job search.

In August many of us are looking ahead to the academic year, and our theme for this issue is on the teaching aspect of our careers. Jessica Sidman will write about inclusive teaching and overcoming student anxiety. Hannah Bennett will write a piece about the Flipped Classroom and Inquiry Based Learning, and Jen Bowen will discuss the supervision of senior theses. Jasmine $\mathrm{Ng}$ will write about teaching at a community college. We also plan to address issues surrounding how to decide what you should teach, how to decide whether or not to revamp the class you've been teaching, and dealing with teaching evaluations.

We depend on letters of recommendation at every stage in our academic careers and for this reason and so many others, it is crucial to develop meaningful and productive professional relationships with experts in our fields. In
September many people either ask, or are asked for letters of recommendation for the coming job market, and so we chose September to feature an issue about how to be a mentor, maintain a good relationship with your mentor, and carry out your mentoring duties. Ken Ono and Bernd Sturmfels will both contribute articles about advising. Ken Ribet will write with general advice to graduate students. Dawei Chen will write about reaching out to experts in your field.

October is our "Work-Life Balance Issue." We will discuss strategies to support your career when non-work situations become more demanding. One of the most important things to do in your early career is hang in there and not quit during the long waiting periods such as when finishing your PhD, waiting for job interviews, and tenure and promotion. We are going to give some practical advice on these issues.

The November issue will be focused on planning ahead for the Joint Meetings. In particular we discuss how to prepare for job market and special session activities. Dawei Chen and Alec Kercheval will write about giving talks of various types. Katelynn Kochalski will give advice on preparing for the Employment Center and Joint Meetings interviews for tenure track jobs.

In December, in our "Best Practices Issue," we plan to look back and give kudos to programs and departments that are doing things that we'd like to see emulated throughout the country. We'd like to disseminate those best practices to make them available for other departments to copy and to give chairs of departments information to take to their administrators in order to gain resources to improve their departments. We plan to highlight ideas that departments have come up with to improve working conditions and work/life balance.

Of course there are many other sources of good information along these lines (and far too many to list here!). We hope this section of the Notices will simply provide more perspectives, from people in the community who are interested in helping you get where you want to go. 